\title{
Pattern of 24 hour intragastric acidity in active duodenal ulcer disease and in healthy controls
}

\author{
H S MERKI, C J FIMMEL, R P WALT, K HARRE, J RÖHMEL, \\ AND L WITZEL \\ From the DRK Hospital, Mark Brandenburg, Department of Gastroenterology, Berlin, FRG, Department of \\ Medicine, University of California at Los Angeles School of Medicine, Los Angeles, California, USA, \\ Department of Therapeutics, University of Nottingham, UK, and Department of Statistics, \\ Arzneimittelforschung, Berlin, FRG
}

SUMmaRY Twenty four hour intragastric acidity was measured by continuous recording using intragastric combined glass electrodes in $\mathbf{4 6}$ duodenal ulcer patients within 48 hours of endoscopic confirmation of active ulceration. Acidity during predefined time periods was compared with that measured in 40 healthy controls without gastrointestinal disease: it was significantly higher in duodenal ulcer patients at all times, but $25 \%$ of ulcer patients had median 24 hour acidity within the interquartile range of the normal group. During the evening $(1800$ to $2200 \mathrm{~h})$ ulcer patients had considerable acidity with a median of $39 \cdot 8(63 \cdot 1-31 \cdot 6) \mathrm{mmol} / \mathrm{l}$ (interquartile range) compared with $5 \cdot 6(22 \cdot 3-0 \cdot 4) \mathrm{mmol} / \mathrm{l}$ of controls. It is suggested that antisecretory treatment be directed to decrease this period of unbuffered acidity, as well as during the night, which is presently considered of prime importance.

The role of gastric acid secretion in the pathogenesis of duodenal ulcer disease is poorly defined. It is agreed, however that as a group duodenal ulcer patients secrete greater quantities of acid than normal subjects. Most formal studies clearly show a large degree of overlap, with approximately $30 \%$ of ulcer patients secreting apparently normal volumes of acid.' Attempts to further separate ulcer patients from the normal group have intimated that differences are most prominent during the night and in response to food. ${ }^{2-6}$ Some workers dispute these differences and claim that methodological problems could explain observations. ${ }^{7}$ Most recently a technique which measures total 24-hour acid secretion has confirmed that duodenal ulcer patients secrete more acid than normal subjects under basal and stimulated conditions. ${ }^{\times}$A circadian pattern of gastric secretion under basal conditions has also been reported for normal subjects" and duodenal ulcer. ${ }^{10}$ In these earlier studies the methods used may have obscured true differences which might occur in real life, and ambulant studies have not previously been

Address for correspondence: Dr Hans S Merki, Department of Gastroenterology, Inselspital Bern, CH-3000 Bern. Switzerland.

Received for publication 4 May 1988. reported. We have used a technique for continuous intragastric $\mathrm{pH}$-measurement which interferes little with daily activity and allows assessment of gastric acidity under conditions of real life. As most previous studies have investigated duodenal ulcer patients in remission, we were interested in measuring acidity during active ulceration. It is believed that the effect of antisecretory drugs on 24-hour gastric acidity, particularly nocturnal acidity, can predict their clinical potential." If true, and consistent differences in acidity between active ulcer disease and normal subjects were found, then the administration of antisecretory drugs to normalise acidity would seem logical.

Table 1 Details of patients and healthy controls

\begin{tabular}{|c|c|c|c|c|}
\hline & \multicolumn{2}{|c|}{$H C$} & \multicolumn{2}{|c|}{$D U$} \\
\hline & $\sigma^{\prime}$ & q & $\sigma$ & q \\
\hline Age: $18-39$ years & 11 & 8 & 14 & 5 \\
\hline $40-59$ years & 5 & 4 & 14 & 5 \\
\hline$>60$ years & 5 & 7 & 6 & 2 \\
\hline Smokers & 8 & 8 & 26 & 7 \\
\hline Non-smokers & 13 & 11 & 8 & 5 \\
\hline
\end{tabular}




\section{Methods}

SUBJECTS

Details of 40 healthy controls (HC) and 46 duodenal ulcer patients (DU) who each underwent one study of 24-hour gastric acidity are shown in Table 1. As would be expected from the pattern of disease, significantly more men and smokers were studied in the DU group. Informed consent was obtained from all subjects and patients and the study was approved by the hospital ethics committee. An endoscopic diagnosis of active duodenal ulcer $>5 \mathrm{~mm}$ (using flexible ruler) was made within 48 hours of each $\mathrm{pH}$ study. Patients already receiving anti-ulcer treatment of any sort, except antacids used for symptoms over a maximum of three days, were excluded. Patients who were taking non-steroidal anti-inflammatory drugs, who had had previous surgery or who also had gastric ulcers were not included. The healthy controls volunteered (in response to local advertisements) and were accepted when there was no present or past history of gastrointestinal disease. Concomitant drug use was banned.

GASTRIC ACIDITY

Four millimetre combined glass electrodes were

Table 2 Caloric values and constituents of meals

\begin{tabular}{|c|c|c|c|c|c|c|}
\hline Time & Meal & $\begin{array}{l}\text { Protein } \\
\text { (g) }\end{array}$ & $\begin{array}{l}\text { Fat } \\
(\mathrm{g})\end{array}$ & $\begin{array}{l}\mathrm{CHO} \\
(\mathrm{g})\end{array}$ & $\begin{array}{l}\text { Dietary } \\
\text { fibre } \\
(\mathrm{g})\end{array}$ & $\begin{array}{l}\text { Energy } \\
\text { value } \\
(k J)\end{array}$ \\
\hline 1600 & $\begin{array}{l}\text { Tea } \\
\text { Cake } \\
\text { Tea } \\
\text { Cream } \\
\text { Sugar }\end{array}$ & $8 \cdot 6$ & $22 \cdot 1$ & $76 \cdot 8$ & $1 \cdot 6$ & 2056 \\
\hline 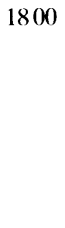 & $\begin{array}{l}\text { Dinner } \\
\text { Wholemeal bread } \\
\text { Ham } \\
\text { Butter } \\
\text { Muesli } \\
\text { Milk } \\
\text { Tea } \\
\text { Sugar }\end{array}$ & 33.9 & $34 \cdot 0$ & $115 \cdot 6$ & $16 \cdot 3$ & 3831 \\
\hline 2200 & $\begin{array}{l}\text { Snack } \\
\text { Banana }\end{array}$ & $1 \cdot 7$ & $0 \cdot 3$ & $35 \cdot 0$ & $3 \cdot 8$ & 624 \\
\hline 0800 & $\begin{array}{l}\text { Breakfast } \\
\text { Rolls } \\
\text { Butter } \\
\text { Jam } \\
\text { Fruit yoghurt } \\
\text { Coffee } \\
\text { Cream } \\
\text { Sugar }\end{array}$ & $18 \cdot 6$ & $28 \cdot 1$ & $122 \cdot 2$ & $3 \cdot 5$ & 3368 \\
\hline \multirow[t]{2}{*}{1200} & $\begin{array}{l}\text { Lunch } \\
\text { Noodle soup } \\
\text { Bread } \\
\text { Chocolate } \\
\text { pudding }\end{array}$ & $9 \cdot 8$ & $6 \cdot 3$ & $59 \cdot 1$ & 3.9 & 1449 \\
\hline & & $72 \cdot 6$ & $90 \cdot 8$ & 408.7 & $29 \cdot 1$ & 11328 \\
\hline
\end{tabular}

passed transnasally into the stomach under fluoroscopic control $(<10 \mathrm{~s} /$ subject) before $1600 \mathrm{~h}$ on the day of study. (Electrode model $440 \mathrm{M} 4, \mathrm{~W}$ Ingold AG, Urdorf, Switzerland.) The $\mathrm{pH}$ was measured and stored every five seconds by a battery powered solid state recorder. This system has been validated for gastric $\mathrm{pH}$ measurement and was used as previously described. ${ }^{12-15}$ Calibration was done at $20^{\circ} \mathrm{C}$ with buffers of $\mathrm{pH} 7 \cdot 00,4.01$, and 1.67 before and after each study. A temperature correction was automatically carried out according to the law of Nernst. Electrode drift of less than $0 \cdot 15 \mathrm{pH}$ units was acceptable.

Standard normal food was eaten (Table 2) at $1600 \mathrm{~h}$ (tea), $1800 \mathrm{~h}$ (dinner), $2200 \mathrm{~h}$ (snack), $0800 \mathrm{~h}$ (breakfast), and $1200 \mathrm{~h}$ (lunch). Cigarette smoking was unrestricted as were the subject's normal daily activities. The studies ran from $1600 \mathrm{~h}$ to $1600 \mathrm{~h}$ the following day. All studies were ambulatory and done in the subjects' own homes. The completed experiment took seven months from May to November 1985.

DATA PROCESSING AND STATISTICAL ANALYSIS Data were transferred first to floppy discs using a Fujitsu computer and then to a larger Harris computer (HS 80). Analyses were done when all data had been collected and the following time periods were predetermined in the protocol for analysis; $1800 \mathrm{~h}-2200 \mathrm{~h}$ (time between supper and the snack), $2200 \mathrm{~h}-0600 \mathrm{~h}$ (night), $0600 \mathrm{~h}-1600 \mathrm{~h}$ (daytime until the end of study), and $1600 \mathrm{~h}-1600 \mathrm{~h}$ (total 24 hours). Median $\mathrm{pH}$ and hydrogen ion activity was calculated with all centiles for individuals and groups. $\mathrm{pH}$ was converted to $\mathrm{H}+$ activity using the standard equation $\mathrm{pH}=3-\log \mathrm{H}+$.

Differences during the time periods above were compared by Wilcoxon's rank-sum tests. An HolmBonferroni alpha adjustment was made for multiple tests. Probability values $\mathrm{p}<0.05$ were considered significant. Graphs of acidity were plotted from five minute median values smoothed by the moving average procedure according to Hamming. ${ }^{\text {it }}$ Comparisons of acidity in smokers and non-smokers, different age groups and sexes were done finally for descriptive purposes.

\section{Results}

Five studies were repeated because of electrode instability or mechanical failure. Twenty four hour acidity was analysed in 46 duodenal ulcer patients and healthy controls. Both groups were reasonably comparable with respect to age, but there were more men and smokers amongst the ulcer patients (Table 1). 
Table 3 Median and interquartile ranges of $p H$ values in DU and HC groups during all time periods. The median is inside the parentheses and the range on either side

Period

\begin{tabular}{llll}
\hline $1600-1600 h$ & $1800-2200 h$ & $2200-0600 h$ & $0600-1600 h$
\end{tabular}

Subjects

\begin{tabular}{|c|c|c|c|c|}
\hline $\mathrm{HC}(\mathrm{n}=40)$ & $1.50(1.6) * 1.90$ & $1.65(2.25) * 3.45$ & $\begin{array}{l}1.30(1.5) * 1.90 \\
1.10\end{array}$ & $\begin{array}{l}1.55(1.70) * 1.95 \\
1.20(1.40) * 1.60\end{array}$ \\
\hline
\end{tabular}

${ }^{*} \mathrm{p}<0.0005$.

Intragastric acidity was significantly higher during all predefined time periods in DU-patients (Table 3 ). Median 24-hour hydrogen ion activity (interquartile range) was $50(63 \cdot 1-31 \cdot 6) \mathrm{mmol} / \mathrm{l}$ in $\mathrm{DU}$ and 25 $(31 \cdot 6-12 \cdot 6) \mathrm{mmol} / \mathrm{l}$ in controls (Fig. 1). From this figure it is clear that median $\mathrm{pH}$ was 1.5 or less in $75 \%$ of DU and was greater than 1.5 in $75 \%$ of $\mathrm{HC}$. The greatest difference between DU and normal was seen during the early evening $(6-10 \mathrm{pm})$ when median hydrogen ion activity was $39 \cdot 8(63 \cdot 1-31 \cdot 6) \mathrm{mmol} / \mathrm{l}$ in DU and $5.6(22.3-0.4) \mathrm{mmol} / \mathrm{l}$ in healthy subjects (Fig. 2). The consistently higher acidity pattern of duodenal ulcer patients throughout the 24-hour
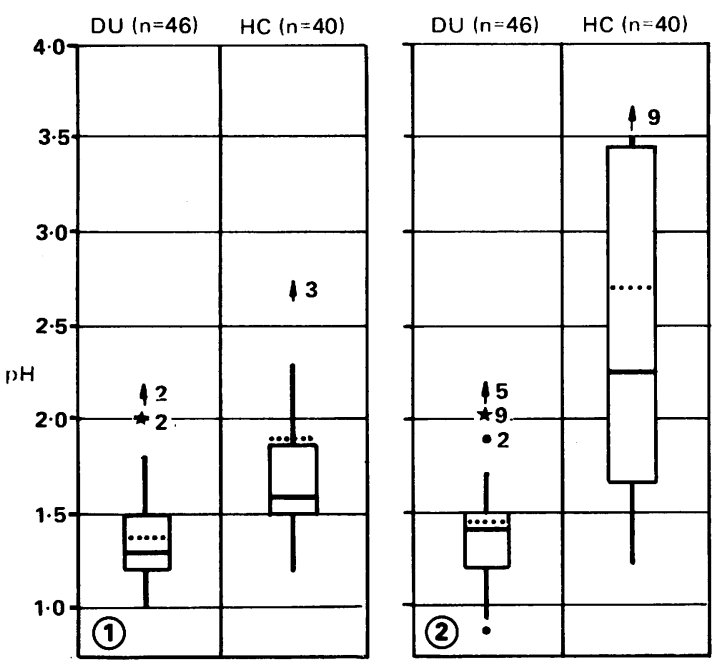

Fig. 1 Box whisker plots of median 24-hour intragastric acidity in $D U$ and $H C$. The solid line shows the median, and the dotted line shows the mean of all the individual medians. The box contains the interquartile range and the whiskers stretch to the furthest value within one interquartile distance $(I Q D)$ from the first and third quartiles. Outliers are shown as points (falling within 1.5 times the IQD from the first and third quartiles), as stars (within two times the IQD etc.) and as arrows if further than twice the IQD etc. ${ }^{17}$

Fig. 2 Box whisker plots of median evening intragastric acidity $(1800-2200 \mathrm{~h})$. For explanation of symbols see legend to Figure 1. period is shown in Figure 3. The effect of smoking, age, and sex on the acidity profiles of both groups is shown in Figure 4 (A-C). In duodenal ulcer patients these factors appear to be unimportant influences on acidity.

\section{Discussion}

These studies confirm the finding of increased intragastric acidity in duodenal ulcer patients even during active ulceration. We have also shown that in duodenal ulcer patients off treatment cigarette smoking does not influence gastric acidity. Female DU patients had similar acidity profiles to the men and increasing age did not influence acidity in duodenal ulcer patients. In contrast, increasing age and female sex were both associated with lower gastric acidity in healthy controls but smoking had no effect. We were unable to fully match age and sex between controls and patients, as former were recruited by advertise-

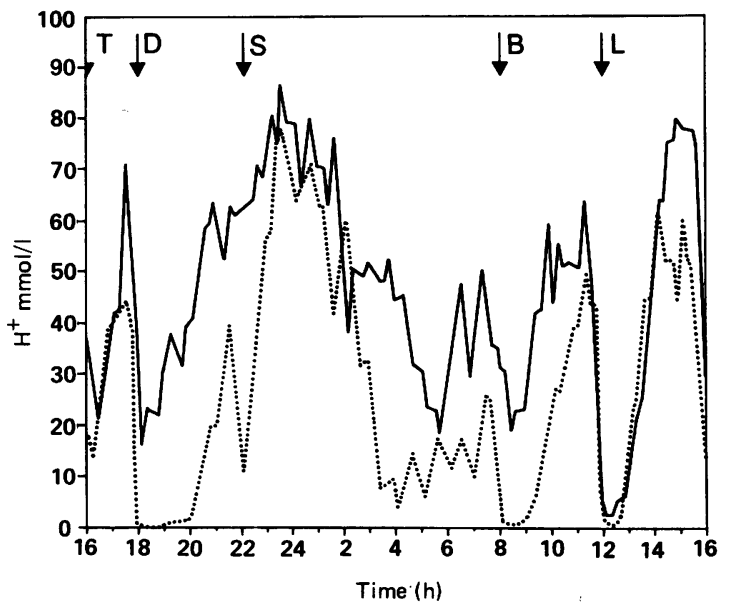

Fig. 3 Median intragastric acidity profiles of $D U$ (solid line) and $\mathrm{HC}$ (broken line) over twenty-four hours. Meals are shown above as tea $(T)$, dinner $(D)$, snack $(S)$, breakfast $(B)$ and lunch $(L)$. Acidity is shown as hydrogen ion activity in mmolll. 

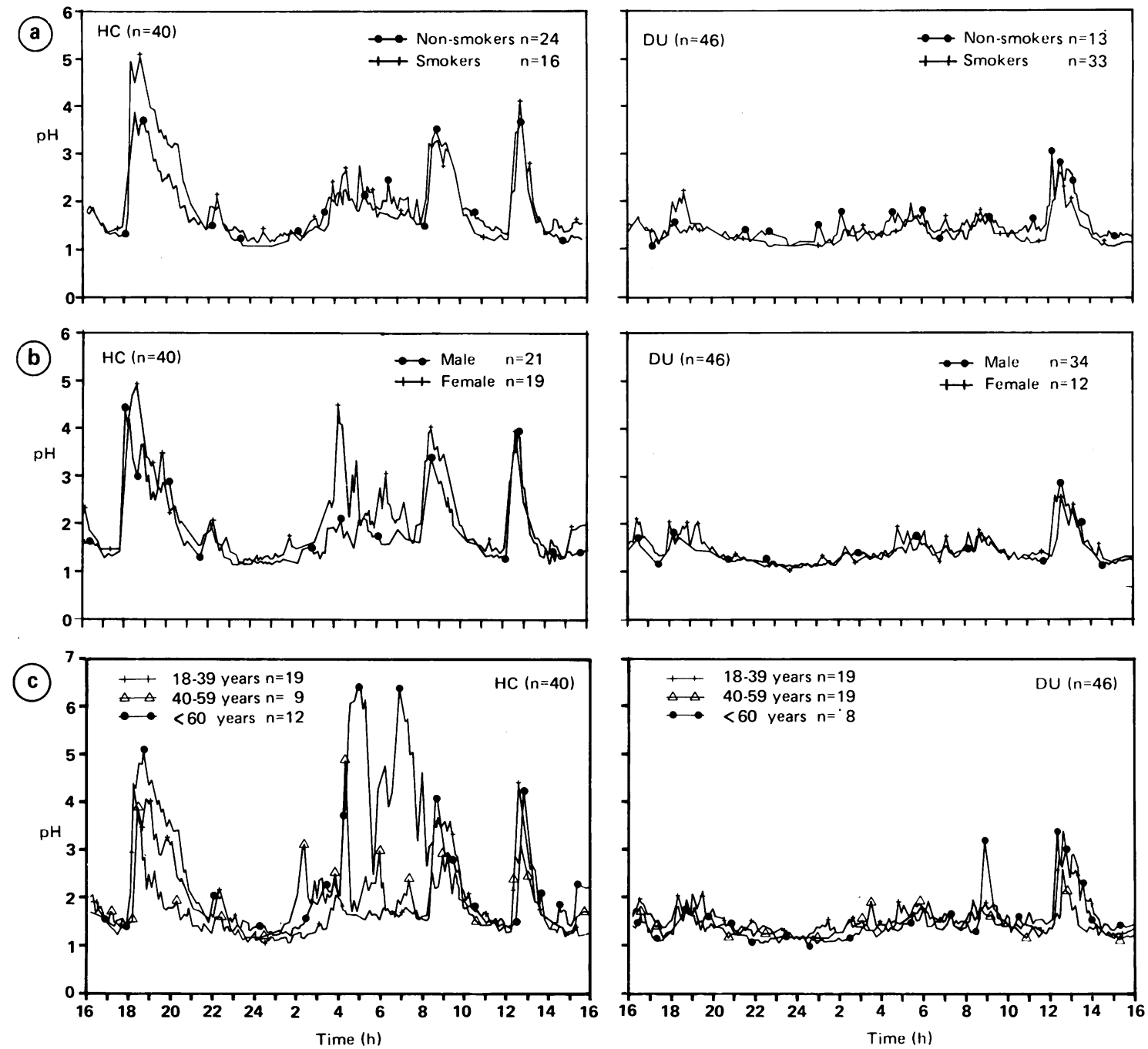

Fig. 4 (a) pH profiles in smokers and non-smokers. DU patients shown on the right $(>0.05$ during all time periods) and HC on the left ( $p<0.051800-2200 \mathrm{~h}$, not significant for all other time periods). (b) pH profiles in men and women (DU: not significant, HC: $p<0.0524$ hour period). (c) pH profiles separated by age 18-39, 40-59, and $>60$ y (DU: not significant, HC: $>60 \vee 40-59$ years: $1800-2200 \mathrm{~h}: \mathrm{p}<0 \cdot 001,>60 v 18-39$ years: $2200-0600 \mathrm{~h}: \mathrm{p}<0 \cdot 01,40-59 v 18-39$ years: $2200-0600 \mathrm{~h}$ : $p<0 \cdot 05$ )

ment. The comparison would, of course, have been more powerful had the groups been better matched. No previous study of adequate size has, however, ever achieved this. It is possible that some of the differences could be explained by the excess of women and middle aged and older subjects in the control group. The finding that amongst duodenal ulcer patients acidity was similar in both sexes and in all age groups, however, suggests that the populations are truly different. Statistical testing of differences between such small subgroups are not strictly valid for two reasons. First, a previous hypothesis had not been made and second the numbers in each subgroup defy adequate statistical analysis. In agreement with previous workers, we have found an overlap of median 24-hour acidity (Fig. 1) which shows that about $25 \%$ of DU-patients fall in the interquartile range of the normal group. During the early evening period $(1800 \mathrm{~h}-2200 \mathrm{~h})$ the overlap was considerably less (Fig. 2). It is not clear why duodenal ulcer patients should have such high acidity during this time. Although the healthy controls ate the same 
meals at the same times as the ulcer patients, the buffering effect of the evening meal seems much less in the latter group. The measuring technique cannot detect differences in the intragastric volume and it is possible that duodenal ulcer patients had a larger amount of gastric juice before this meal than the normal group. This would have considerably lessened any buffering effect of food. Alternatively, gastric emptying (also undetectable with this technique) may have been faster in patients with active ulcers, as previously suggested. ${ }^{6}$

It has been shown in normal subjects and duodenal ulcer patients that basal acid secretion follows a circadian rhythm ${ }^{911}$ with a rise during the evening to a peak around midnight followed by a falling off during sleep. A similar pattern of acidity was found in our DU group. Differences between the acidity of duodenal ulcer and normal subjects are also found during the day. It is therefore difficult to understand why inhibition of nocturnal acidity alone seems to be therapeutically important, particularly if one considers the fact that after midnight gastric secretion falls to low levels even in duodenal ulcer. ${ }^{8}$ It seems likely that prolonged periods of high acidity (albeit of low volume) are important and these occur when food is not taken. At present pharmacological inhibition of gastric secretion is aimed at night with bedtime dosing of $\mathrm{H} 2$-receptor antagonists. As considerable acidity is present in the prebedtime evening period, adjustment of dosage timing would seem reasonable at least for duodenal ulcer therapy. In this study the greatest difference between patients and healthy controls was found in the evening and it seems logical to take steps to decrease these differences if possible. Other studies have already shown that some drugs administered early in the evening can effectively decrease gastric acidity during this period as well as throughout the night. ${ }^{14}$ Clinical trials with new dosage schedules are needed to test the hypothesis that high evening acidity as well as nocturnal acidity is of pathophysiological importance.

\section{References}

1 Baron $\mathrm{JH}$. The relationship between basal and maxi- mum acid output in normal subjects and patients with duodenal ulcer. Clin Sci 1963; 24: 357-70.

2 Dragsted LR. Gastric secretion tests. Gastroenterology 1967; 52: 587-9.

3 Levin E, Kirsner JB, Palmer WL, Butler C. A comparison of the nocturnal gastric secretion in patients with duodenal ulcer and in normal individuals. Gastroenterology 1948; 10: 952-64.

4 Palmer WL, Templeton F. The effect of radiation therapy on gastric secretion. JAMA 1939; 112: 1939.

5 Atkinson M, Henley KS. Levels of intragastric and intraduodenal acidity. Clin Sci 1955; 14: 1-14.

6 Fordtran JS, Walsh JH. Gastric acid secretion rate and buffer content of the stomach after eating. J Clin Invest 1973; 52: 645-57.

7 Faber R, Hobsley M. Basal gastric secretion: reproducibility and relationship with duodenal ulceration. Gut 1977; 18: 57-63.

8 Feldmann M, Richardson CT. Total 24-hour gastric acid secretion in patients with duodenal ulcer. Comparison with normal subjects and effects of cimetidine and parictal cell vagotomy. Gastroenterology 1986; 90: 540-4.

9 Moore JG, Halberg F. Circadian rhythm of gastric acid secretion in man. Nature 1970; 226: 1261-2.

10 Moore JG, Halberg F. Circadian rhythm of gastric acid secretion in men with active duodenal ulcer. Dig Dis Sci 1986; 31: 1185-91.

11 Hunt RH, Howden CW, Jones DB, Burget FW, Kerr GD. The correlation between acid suppression and peptic ulcer healing. Scand J Gastroenterol [Supp] 1986; 21: 22-9.

12 Fimmel CJ, Etienne A, Ciluffo $\mathrm{T}$, et al. Long term ambulatory gastric $\mathrm{pH}$ monitoring: Validation of a new method and effect of $\mathrm{H} 2$-antagonists. Gastroenterology 1985; 88: 1842-51.

13 Etienne A, Fimmel CJ, Bron BA, Loizeau E, Blum AL. Evaluation of pirenzepine on gastric acidity in healthy volunteers using ambulatory 24-hour intragastric $\mathrm{pH}$ monitoring. Gut 1985; 26: 241-5.

14 Merki H, Witzel L, Harre K, Scheurle E, Neumann J, Röhmel J. Single dose treatment with H2-receptor antagonists: Is bedtime administration too late? Gut 1987; 28: 451-4.

15 Merki H, Witzel L, Walt R, et al. Day to day variation of 24-hour intragastric acidity. Gastroenterology 1988; 94: 887-91.

16 Hamming RW. Numerical methods for scientists and engineers. New York: McGraw-Hill, 1973.

17 McGill R. Tukey JW, Larsen WA. Variation of Box Plots. Am Statistician 1978; 32: 12-7. 